\title{
Studying Parameter Sensitivity and Behaviour of the Crop Model STICS
}

\author{
A.I. Heuer* and M.C. Casper
}

University of Trier, Department of Physical Geography, Behringstraße 21, D-54286 Trier, Germany

\begin{abstract}
The present article shows the results of a study on the soil module of the STICS (Simulateur Multidisciplinaire des Cultures Standards, developed by INRA, France) crop model. Simulation models are often applied to regions where conditions are substantially different from the ones which the model was originally developed for and validated against. This was the reason to study the sensitivity of the STICS soil module and to analyze model behavior with regard to spatial transferability. The model was parameterized with data collected from an area close to the German city of Trier. Using this parameterization as a baseline, an initial study was carried out on the sensitivity of the soil parameters. This was followed by an analysis of model behavior concerning parameters which also in the real system are responsible for successful or poor plant growth. This provided some improvements over the initial simulation results. However, the model failed to match the real system's behavior concerning yield, biomass development, and root growth. From various approaches to parameterization it has become clear that a high level of abstraction is required to produce a satisfactory model of the soil-plant-atmosphere continuum and in particular the soil water dynamics. This applies especially to extreme locations as well as to relatively extreme climatic years.
\end{abstract}

Keywords: Crop model, STICS, soil module, soil water balance, evaporation, sensitivity, model behavior, Monte Carlo simulation, parameter error, spatial transfer.

\section{INTRODUCTION}

Crop models and soil-crop models are used for a number of different purposes such as simulating crop growth or yield and calculating water, nitrogen or carbon balances [1-3].

Typically, the first step towards applying a given model is to perform parameterization, using data directly or indirectly derived from measurements in the field. Often, however, models are applied to regions that do not match the environment which they were originally developed for and validated against. For example, in [4-6] one and the same dataset was used to compare distinct types of models. Besides, (soil-)crop models are often applied at a range of scales, even at the meso- or macroscale [7-10]. Thus, a spatial transfer of the model has to be assumed. This necessitates locally adopted model parameters, which is particularly relevant for conceptual (or "empirical") model parameters.

The present study attempts to address the validity issue by investigating the soil module and the soil water balance of STICS (Simulateur Multidisciplinaire des Cultures Standards), a crop model developed by the Institut National de la Recherche Agronomique (INRA), France [11-13]. One of the model's key elements is the integration of a broad range of crops and even crop varieties; common crops of the genus Triticum (wheat), Hordeum (barley) and Zea (maize) and also less frequent crops of the genus Vitis (grape), Musa (banana) and Oryza (rice) can be simulated with STICS. This

\footnotetext{
*Address correspondence to this author at the University of Trier, Department of Physical Geography, Behringstraße 21, D-54286 Trier, Germany; Tel: ++49 - 651 - 201 4524; Fax: ++49 - 651 - 201 3976;

E-mail: heuer@uni-trier.de
}

makes it possible to apply the model to a large number of given situations and different regions in France, Europe and beyond [14-17]. The following questions arise: How is the natural system represented within the model? Which of the soil parameters play a central role in the model? Is the soil module sensible with regard to extreme locations as well as for extreme climatic years?

To investigate the sensitivity of the soil module and to analyze model behavior the model was parameterized first with data collected in the field. Additional field data made it possible to validate the results with regard to the target variables yield, above ground dry matter and rooting depth. Knowledge of the natural system was used to adapt experimentally derivable parameters, whereas a Monte Carlo simulation was used to adapt immeasurable parameters. Finally the STICS model and the soil module itself were evaluated, considering the natural system and the model structure (see Fig. 1).

\section{MATERIALS AND METHODOLOGY}

\subsection{Study Area}

This study was conducted in the area of Newel which is located in the Bitburger Gutland in Western RhinelandPalatinate, Germany. The geology of the study area is dominated by shallow limestone formations. The soil is clayey with high carbonate content and frequently of low depth [18, 19]. Capillary rise can be excluded as the groundwater table is rather deep. The long-term mean annual precipitation is around $780 \mathrm{~mm} \mathrm{y}^{-1}$, the mean annual temperature is $9.1^{\circ} \mathrm{C}$ [20]. 


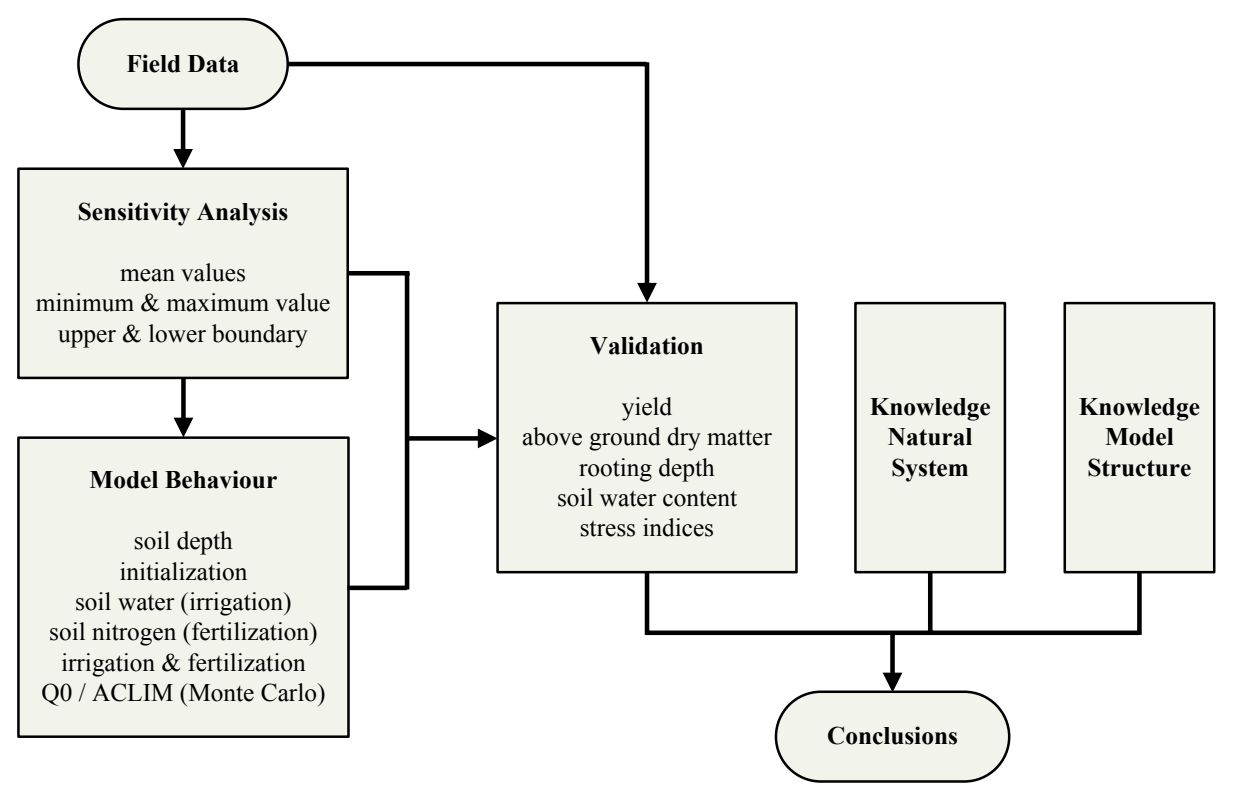

Fig. (1). Flow chart illustrating the investigation scheme.

For the present investigation, a plot of cropland was chosen which had been conventionally cultivated with a crop rotation of winter rape, winter wheat and spring barley. The model simulation extends over a time period from 2001 to 2005, although initialization runs were made over the first three years, and only the 2005 spring barley was considered for the analysis.

\subsection{Database}

Before, during, and after the vegetation period of spring barley, various types of data were collected. Generally this was either the data used to derive STICS parameters, or in turn the data used to validate the model results. Field data is specified in Table $\mathbf{1}$ by its mean value and by the range of the data (minimum and maximum values), taking natural

Table 1. Range of Collected Soil Data Used to Parameterize and to Validate the Model

\begin{tabular}{|c|c|c|c|c|c|}
\hline & Parameter & Description Parameter & Minimum Value & Mean & Maximum value \\
\hline \multirow{5}{*}{$\begin{array}{l}\text { Parameterizing } \\
\text { - first horizon - }\end{array}$} & $\operatorname{argi}$ & Clay content $[\%$ mass $]$ & 23.7 & 26.3 & 28.4 \\
\hline & Norg & Organic nitrogen [\% mass] & 0.05 & 0.23 & 0.3 \\
\hline & calc & $\mathrm{CaCO}_{3}$ content $[\%$ mass $]$ & 0.5 & 2.09 & 4.0 \\
\hline & $\mathrm{pH}$ & $\mathrm{pH}$ & 7.33 & 7.51 & 7.9 \\
\hline & obstarac & Soil depth $[\mathrm{cm}]$ & 42.0 & 57.0 & 77.0 \\
\hline \multirow[t]{5}{*}{$\begin{array}{l}\text { Parameterizing } \\
\text { - all horizons - }\end{array}$} & $\begin{array}{l}\text { ерc(1) } \\
\text { ерc(2) } \\
\text { ерc(3) } \\
\text { ерс(4) }\end{array}$ & Thickness horizon [cm] & $\begin{array}{l}10.0 \\
10.0 \\
12.0 \\
10.0\end{array}$ & $\begin{array}{l}12.0 \\
15.0 \\
15.0 \\
15.0\end{array}$ & $\begin{array}{l}15.0 \\
18.0 \\
17.0 \\
27.0\end{array}$ \\
\hline & $\begin{array}{l}\operatorname{hccf}(1) \\
\operatorname{hccf}(2) \\
\operatorname{hccf}(3) \\
\operatorname{hccf}(4)\end{array}$ & $\begin{array}{l}\text { Soil moisture } \\
\text { at field capacity [\% mass] }\end{array}$ & $\begin{array}{l}22.1 \\
16.9 \\
17.4 \\
14.6\end{array}$ & $\begin{array}{l}24.5 \\
18.9 \\
19.3 \\
16.2\end{array}$ & $\begin{array}{l}27.0 \\
20.7 \\
21.2 \\
17.8\end{array}$ \\
\hline & $\begin{array}{l}\operatorname{hminf}(1) \\
h \operatorname{minf}(2) \\
h \operatorname{minf}(3) \\
h \operatorname{minf}(4)\end{array}$ & $\begin{array}{l}\text { Soil moisture } \\
\text { at wilting point }[\% \text { mass }]\end{array}$ & $\begin{array}{c}15.0 \\
14.0 \\
14.2 \\
9.1\end{array}$ & $\begin{array}{l}16.7 \\
15.5 \\
15.8 \\
10.1\end{array}$ & $\begin{array}{l}18.4 \\
17.1 \\
17.4 \\
11.1\end{array}$ \\
\hline & $\begin{array}{l}\operatorname{daf}(1) \\
\operatorname{daf}(2) \\
\operatorname{daf}(3) \\
\operatorname{daf}(4)\end{array}$ & $\begin{array}{l}\text { Dry bulk density } \\
{\left[\mathrm{g} / \mathrm{cm}^{3}\right]}\end{array}$ & $\begin{array}{l}1.41 \\
1.57 \\
1.51 \\
1.70\end{array}$ & $\begin{array}{l}1.46 \\
1.62 \\
1.60 \\
1.79\end{array}$ & $\begin{array}{l}1.52 \\
1.65 \\
1.65 \\
1.88\end{array}$ \\
\hline & $\begin{array}{l}\text { cailloux(1) } \\
\text { cailloux(2) } \\
\text { cailloux(3) } \\
\text { cailloux(4) }\end{array}$ & $\begin{array}{c}\text { Stones, skeletal soil } \\
{[\% \text { vol. }]}\end{array}$ & $\begin{array}{c}2.0 \\
2.0 \\
2.0 \\
10.0\end{array}$ & $\begin{array}{c}6.6 \\
2.8 \\
7.8 \\
17.5\end{array}$ & $\begin{array}{l}10.0 \\
10.0 \\
10.0 \\
25.0\end{array}$ \\
\hline
\end{tabular}


Table 1. contd...

\begin{tabular}{|c|c|c|c|c|c|}
\hline & Parameter & Description Parameter & Minimum Value & Mean & Maximum value \\
\hline \multirow{4}{*}{$\begin{array}{c}\text { Validation } \\
\text { - singular mapping - }\end{array}$} & pdsfruitfrais & Yield [t/ha] & 5.5 & 6.0 & 6.5 \\
\hline & masec & $\begin{array}{l}\text { Above ground dry matter (maximum } \\
\text { value) [t/ha] }\end{array}$ & 11.2 & 12.1 & 13.0 \\
\hline & zrac & Rooting depth (maximum value) $[\mathrm{cm}]$ & 65.0 & 72.0 & 80.0 \\
\hline & $\begin{array}{l}\text { Swfac } \\
\text { turfac } \\
\text { inns }\end{array}$ & $\begin{array}{c}\text { Stomatic water stress, } \\
\text { turgescence water stress, } \\
\text { nitrogen stress of the plant [-] }\end{array}$ & \multicolumn{3}{|c|}{ - see Table 4 - } \\
\hline $\begin{array}{c}\text { Validation } \\
\text { - repeated mapping of all } \\
\text { horizons - }\end{array}$ & $\begin{array}{l}\operatorname{HR}(1) \\
\operatorname{HR}(2) \\
\operatorname{HR}(3) \\
\operatorname{HR}(4)\end{array}$ & $\begin{array}{l}\text { soil moisture } \\
{[\% \text { mass }]}\end{array}$ & \multicolumn{3}{|c|}{ - see Fig. (5) - } \\
\hline
\end{tabular}

\section{Parameters}

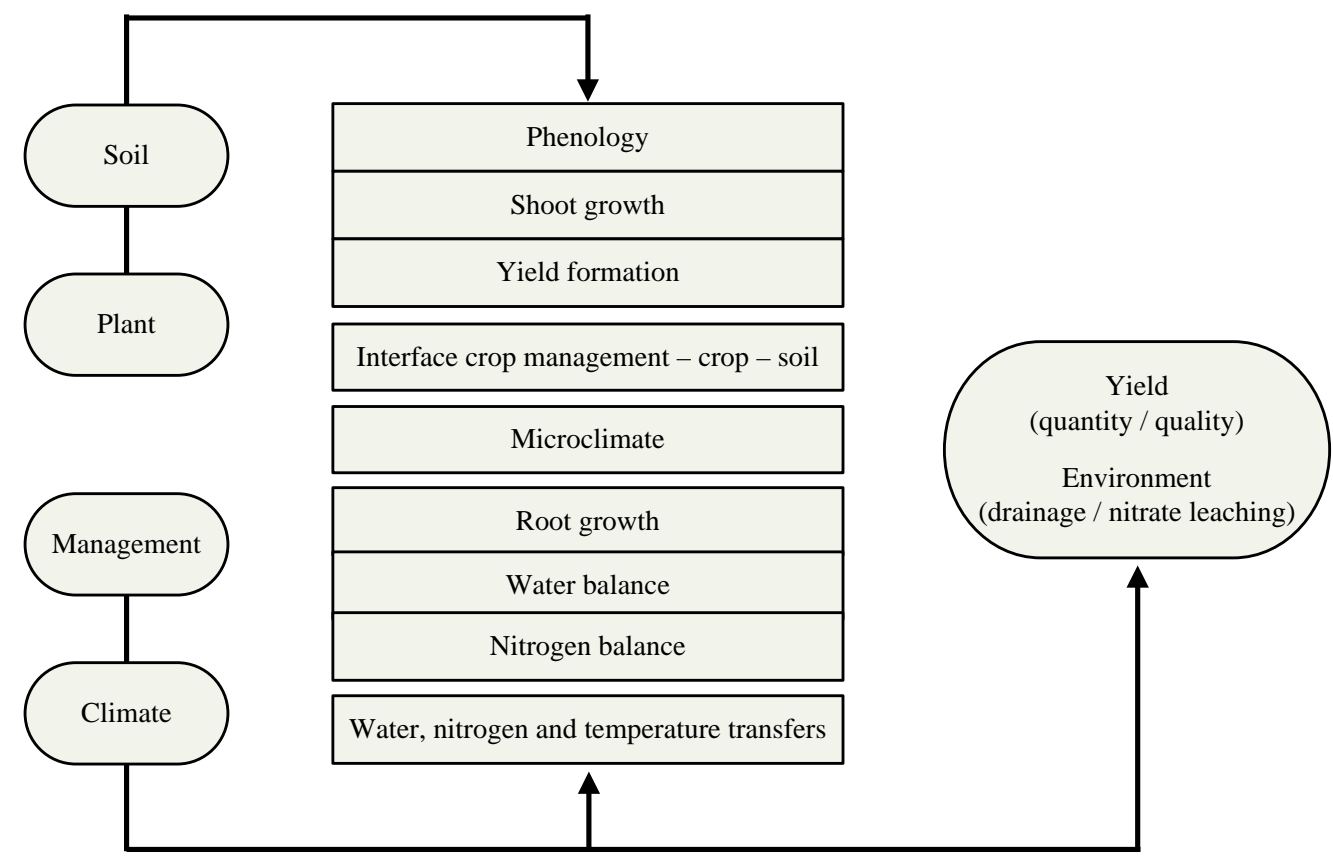

\section{Input}

Modules

Output

Fig. (2). Overview of the model system and its components; based on [13].

variability and possible measurement errors into consideration.

Climate data was obtained from the meteorological station Trier-Petrisberg ( $265 \mathrm{~m}$ altitude) which is about $10 \mathrm{~km}$ away from the study area; precipitation though was adjusted with measurements on the test site itself.

\subsection{The Model}

STICS is a dynamic crop model which simulates the behavior of the soil-crop system over one or several crops. The upper and lower limits of the model are the atmosphere and the soil / subsoil interface, respectively. The model requires information about initial and permanent conditions of soil, plant functioning and crop management and is driven by daily climatic data (solar radiation, minimum and maximum temperature, precipitation and reference evapotranspiration).

The model is composed of a number of modules, see Fig. (2). There are modules that deal with: i) the physiology of the aboveground plant parts, ii) the interactions between the crop management and the soil-crop system, iii) the microclimate, and iv) the interactions between soil and subsurface plant parts (Fig. 2).

The main simulated processes are the crop growth and development as well as the water and nitrogen balances in the soil and crop. A detailed overview of the model itself is given in [11-13]. The present paper focuses on the submodules soil and soil water balance as well as the actual evaporation of soil. 


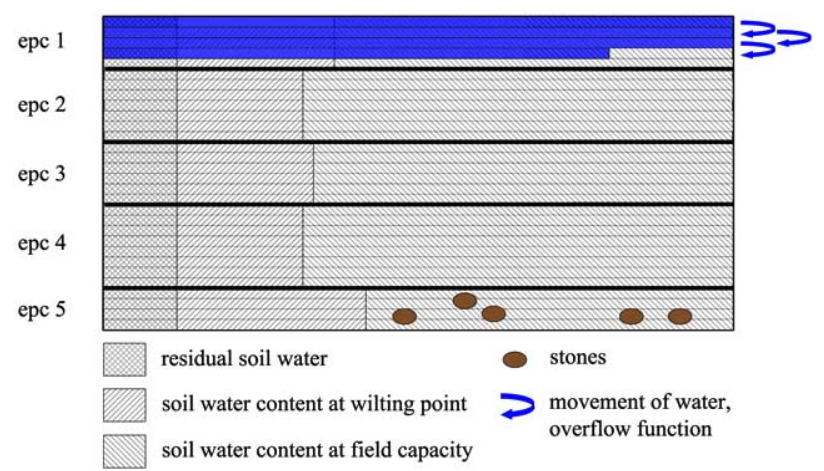

Fig. (3). Organization of the STICS soil module; macropores and cracks are not considered in the investigation and therefore not indicated; figure based on [23].

\subsubsection{Soil and Soil Water Balance}

One of the model's sub-modules is the soil module. There, soil is built up of a sequence of pedological discontinuities or horizons. Each horizon is characterized by its microporosity (consisting of residual soil water, soil water content at wilting point and soil water content at field capacity) and optionally by macropores, cracks, and stones. The soil's microporosity is the basis for calculating soil water as well as soil nitrogen balance.

The soil water flux is described by a 'layer-approach' where the soil is subdivided into basic horizontal layers of 1 $\mathrm{cm}$ thickness which act as a reservoir with an overflow function. Water moves downwards from one layer to the next as the soil moisture within a layer reaches the layer's field capacity, as shown in Fig. (3).

\subsubsection{Actual Evaporation from Soil Surface}

In STICS, actual evaporation from soil surface is modeled to occur in two stages (cf. Fig. 4). After a rainfall event, the first stage sets in where evaporation is considered to be potential for as long as the accumulated evaporation is below a certain threshold value, Q0 (equation (1)). Thus, Q0 is a surface property independent of field capacity. It describes the amount of water $[\mathrm{mm}]$ that is considered to evaporate potentially from bare soil after a rainfall event (end of stage I). Above Q0, actual evaporation from soil surface is lessened, dependent on climate and soil (equation (2)), [21-23]. Daily evaporation calculated in this manner affects soil (discretized to layers of $1 \mathrm{~cm}$ thickness) exponentially decreas-

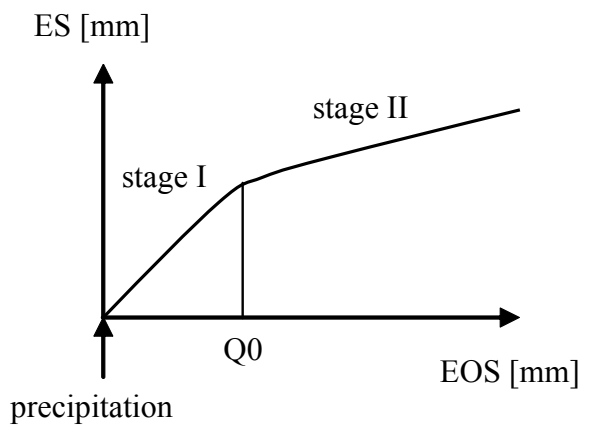

Fig. (4). Subdivision of actual evaporation into two stages by means of the threshold value Q0 [23] and corresponding equations to calculate actual evaporation according to [22]. ing, starting from soil surface to a defined soil depth (default $=60 \mathrm{~cm})[23]$.

Stage I.

$\sum_{t_{0}}^{t_{n}} E S=\sum_{t_{0}}^{t_{n}} E O S$

$\mathrm{ES}=$ actual evaporation from soil $[\mathrm{mm} / \mathrm{d}]$

EOS $=$ potential evaporation from soil $[\mathrm{mm} / \mathrm{d}]$

Stage II.

$\sum_{\mathrm{t}_{0}}^{\mathrm{t}_{\mathrm{n}}} \mathrm{ES}=\left(2 \mathrm{~A} * \sum_{\mathrm{t}_{0}}^{\mathrm{t}_{\mathrm{n}}} \mathrm{ESO}+\mathrm{A}^{2}\right)^{\frac{1}{2}}-\mathrm{A}$

With:

$\mathrm{A}=\frac{1}{2} \mathrm{ACLIM} * \mathrm{ASOIL}$

Which is:

$$
\mathrm{A}=\frac{1}{2}\left[\frac{\mathrm{P}^{\prime}+\Gamma}{\Gamma}(\mathrm{L})(\mathrm{ARS})\left(\mathrm{D}_{0}\right)\right] *\left[\left(\frac{\mathrm{D}}{\mathrm{D}_{0}}\right)\left(\theta_{0}-\theta_{\mathrm{r}}\right)\right]
$$

ACLIM $=$ climatic component of $\mathrm{A} \mathrm{[-]}$

ASOIL $=$ soil component of A [-]

$\mathrm{P}^{\prime} \quad=$ slope of saturation vapor pressure versus temperature for water [-]

$\Gamma=$ total psychrometric constant $\left[\mathrm{mbar} /{ }^{\circ} \mathrm{C}\right]$

$\mathrm{L}=$ latent heat of vaporization of liquid water $\left[\mathrm{J} / \mathrm{m}^{3}\right]$

ARS = aerodynamic resistance at the soilatmosphere interface [ $\mathrm{sec} / \mathrm{m}$ ]

D $=$ molecular diffusion coefficient within mulch $\left[\mathrm{m}^{2} / \mathrm{sec}\right]$

$\mathrm{D}_{0}=$ molecular diffusion coefficient in atmosphere $\left[\mathrm{m}^{2} / \mathrm{sec}\right]$

$\theta_{0} \quad=\quad$ initial soil moisture $\left[\mathrm{m}^{3} / \mathrm{m}^{3}\right]$

$\theta_{\mathrm{r}} \quad=\quad$ residual soil moisture $\left[\mathrm{m}^{3} / \mathrm{m}^{3}\right]$

Q0 as a model parameter is difficult to obtain experimentally; it has been necessary to base the parameterization on values suggested in existing literature. Unfortunately, only two references were found that state values for Q0 [21, 22]. In addition the recommended values differ extremely, although both references define the value of Q0 according to the amount of clay in the soil (Table 2). Another parameter that affects evaporation from soil is ACLIM. It is a climatic component that also is not directly measurable but needs to be derived from wind speed (annual average). A more detailed description of the model, its structure and interlinkages is given in [23].

\subsection{PARAMETERIZATION SCHEME}

\subsubsection{Sensitivity Analysis}

The sensitivity analysis is based on a reasonable range of parameters derived from field measurements. It can be divided into three steps. 
Table 2. Values for Q0 and ACLIM as Suggested by Literature and as Applied in the Monte Carlo Analysis

\begin{tabular}{|c|c|c|}
\hline Range According to... & Q0 & ACLIM \\
\hline \hline general suggestions according to [21-22] & $0-22$ & $14-20$ \\
\hline suggestion for clay content +/- 26\% according to [21] & $9-12$ & - \\
\hline suggestion for clay content +/- 26\% according to [22] & 22 & - \\
\hline applied to Monte Carlo simulation & $0-22$ & $10-30$ \\
\hline
\end{tabular}

Table 3. Partial Sensitivity of the Soil Module Parameters and Resulting Parameter Ranking

\begin{tabular}{|c|c|c|c|c|c|}
\hline \multirow[t]{2}{*}{ Parameter $^{(1)}$} & \multicolumn{4}{|c|}{ Partial Gain } & \multirow[t]{2}{*}{ Ranking } \\
\hline & $\begin{array}{l}\text { Yield } \\
\text { [t/ha] }\end{array}$ & $\begin{array}{l}\text { Yield } \\
{[\%]}\end{array}$ & $\begin{array}{c}\text { dry matter }{ }^{(2)} \\
{[\mathrm{t} / \mathrm{ha}]}\end{array}$ & $\begin{array}{c}\text { dry matter }{ }^{(2)} \\
{[\%]}\end{array}$ & \\
\hline observed & 6.00 & - & 12.1 & - & \\
\hline basic & 0.96 & 100.00 & 2.28 & 100.00 & \\
\hline albedo bare soil & +0.02 & +2.04 & +0.08 & +3.39 & 6 \\
\hline $\operatorname{argi}$ & +0.00 & +0.00 & +0.00 & +0.00 & 10 \\
\hline Norg & +0.01 & +1.03 & +0.04 & +1.72 & 8 \\
\hline calc & +0.00 & +0.00 & +0.01 & +0.44 & 9 \\
\hline $\mathrm{pH}$ & +0.00 & +0.00 & +0.00 & +0.00 & 10 \\
\hline Q0 & +0.22 & +18.64 & +0.54 & +19.15 & 3 \\
\hline epc, obstarac & +0.16 & +14.29 & +0.37 & +13.96 & 4 \\
\hline hecf & +0.33 & +25.58 & +0.82 & +26.54 & 1 \\
\hline hminf & +0.25 & +20.66 & +0.58 & +20.28 & 2 \\
\hline daf & +0.05 & +4.95 & +0.13 & +5.39 & 5 \\
\hline cailloux & +0.02 & +2.04 & +0.05 & +2.15 & 7 \\
\hline upper boundary & +2.20 & +69.62 & +4.79 & +67.75 & \\
\hline
\end{tabular}

for further description of parameters see sections 2.2 and 2.3 .2

(2) dry matter $=$ above ground dry matter

1. Based on the mean values of data collected in the field as well as the standard values set by the model itself [23] and the information given by relevant literature [24, 25], a basic parameterization of the mfodel was defined. This parameter set (basic parameterization) served as the basis for a sensitivity study of all parameters of the soil module.

2. According to the range of spatial conditions and soil properties measured in the field, the parameterization scheme for every single soil parameter of the model involved two further runs using the measured parameter's numerical minimum and maximum values, correspondingly. All other soil parameters were set to their mean values. In this way the degree of sensitivity for every soil parameter could be determined. At the same time, the tendency of the sensitivity with regard to the target variables and the stress indices (see section 2.5 'Validation scheme') could be identified.

The impact of a single soil parameter (p) on a given target variable can be calculated as follows:
$\mathrm{S}=\frac{\mathrm{p}-\mathrm{b}}{\mathrm{p}} * 100 \quad[\%]$

$\mathrm{S}=$ partial sensitivity

$\mathrm{p}=$ numerical value of a target variable, as result of parameterizing the soil module with minimum or maximum values per soil parameter, respectively

$\mathrm{b}=$ numerical value of a target variable, as result of parameterizing the soil module with mean values only

3. Now, as soil parameters were known to either constrain or enhance the target variables the sensitivity study could be supplemented by two "extreme" simulations. This is on one hand a parameterization of the soil module with values that all constrain the target variables, thus defining the lower boundary of model output. On the other hand a parameterization of the soil module with values that all support the target variables, thus identifying an upper boundary. These boundaries made it possible to determine the maximum possible range of the target variables (see Table $\mathbf{3}$ ). 


\subsubsection{Analysis of Model Behaviour}

Given the sensitivity analysis results, six approaches ((A) to $(\mathrm{F}))$ were carried out as described in the following. Aim of these parameterization approaches is to further analyze model behavior and to optimize, that is to maximize, target variables. As water balance and especially soil water balance turned out to play a central part in STICS, the analysis concerns those parameters which are known to directly or indirectly relate to (soil) water balance. The parameters that considerably limit or stimulate plant growth in the real system as well as parameters that are difficult to estimate. Model behavior again is validated by the target variables as mentioned in section 2.5. The analysis of model behavior includes the following approaches:

A. One of the parameters that was adjusted is soil depth. Initially this parameter was set to $57 \mathrm{~cm}$, purely from a point of view of soil science, taking into account the observed dense and stagnic mineral subsoil horizon or weathered mineral subsoil horizon. However, the amount of soil exhausted by plants can be much larger [26]; therefore, the soil depth value was increased to $200 \mathrm{~cm}$ (approach (A)).

B. Furthermore, the warm-up period of the model was initialized with regard to the soil's content of water, nitrate and ammonia. This ensured that by 2005 (the year of evaluation) the effect of the user's estimates on initial state variables would be minimized and that the model would have reached reasonable starting values for the mentioned model state variables, comparable to the conditions in the field (approach (B)).

C. The permanent and sufficient presence of water in the soil is vital to plant growth, not only because plants need water for both growth and transpiration, but also because water contains nutrients in solution. The STICS model allows water stress effects to be reduced by activating artificial irrigation. Model parameters were adjusted to apply an automatic irrigation of $10 \mathrm{~mm}$ for water stress (water stress index $=0.7)$, approach $(C))$.

D. Besides water stress, the STICS model also allows nitrogen stress effects to be reduced by activating artificial mineral fertilization. Again, model parameters were adjusted to apply an automatic fertilization of $10 \mathrm{~kg} \mathrm{~N} / \mathrm{ha}$ for nitrogen stress (nitrogen stress index $=0.7)$, (approach $(\mathrm{D})$ ).

E. Combining artificial irrigation and artificial fertilization, as described above, lead to a further approach, summarized as run $(\mathrm{E})$.

F. The uncertainties related to the model's input parameters Q0 and ACLIM, as explained in section 2.3.2, gave rise to implementing as part of this study a Monte Carlo simulation tool for STICS. Monte Carlo analysis is based on performing multiple evaluations with randomly selected model input. The results of these evaluations are used to determine uncertainty in model predictions and to apportion to the input factors their contribution to this uncertainty [27]. The ranges for Q0 and ACLIM in the Monte Carlo simulation were set based on generally suggested values for Q0 and ACLIM [21, 22] and suggestions for clayey soils (as present in the study area), see Table 2.

In order to re-sample the parameters Q0 and ACLIM a random sampling was used generating a uniformly distrib- uted pseudorandom matrix. The two parameters sampled were assumed to be independent; they do not show any interaction nor implausible combinations of the two parameters exist.

The purpose of the simulation was to narrow down the optimal value range for Q0 and ACLIM, to map the efficiency of these two parameters and finally to improve the parameterization scheme. The number of simulation runs was set to 10000 , allowing for 100 samples per parameter (approach $(\mathrm{F}))$.

\subsection{Validation Scheme}

The validation is geared to the aim of the investigation that is to examine the soil module in more detail. Generally, the results of running each parameterization and model run were visually validated with regard to the target variables 'yield [t/ha]', 'above ground dry matter [t/ha]', and 'rooting depth (maximum value) [cm]'. In addition, the development of the following stress indices was observed: 'stomatic water stress', 'turgescence water stress', and 'nitrogen stress' (all integrated into the model). Each of these stress indices may vary between 1.0 (no stress) and 0.0 (maximal stress). Evaluating the stress indices enabled us to make statements on the intensity, the precise point of time and the duration of stress.

For the model runs concerning the sensitivity analysis, the partial gain of the target variables compared to the basic parameterization ( $=$ mean value for all soil module parameters) was identified for every single parameter of the soil module. The degree of sensitivity of a parameter resulted in a ranking of all investigated parameters. Furthermore, the collective influence of all the target variables supporting values (= upper boundary) on the amount of yield and above ground dry matter was determined.

For the model runs concerning the analysis of model behavior in addition to the above mentioned target variables and stress indices, the soil moisture of every single soil horizon was compared with on-site measurements of soil water contents.

As for the Monte Carlo simulation, the results were first evaluated by comparing the distribution of the target variables and the input variables. In addition, two contrasting pairs of variables of Q0 and ACLIM were chosen to investigate their influence on the target variables and on the stress indices.

\section{RESULTS}

\subsection{Sensitivity Analysis}

The results of the sensitivity analysis of the soil module parameters are summarized in Table 3. The soil properties which under the given conditions showed distinctive reactions are hccf (the soil's water content at field capacity), hminf (the wilting point), Q0 (the amount of water that is considered to evaporate potentially from bare soil after a rainfall event) and epc / obstarac (the soil depth).

Neither the real yield nor the above ground dry matter could be convincingly reproduced by the basic parameterization (Table 3). In addition, considerable water stress oc- 
Table 4. Comparing Measured Data, Basic Parameterization and Following Parameterization Strategies with Regard to Target Variables and Stress Indices

\begin{tabular}{|c|c|c|c|c|c|c|c|}
\hline Run & Parameterization Scheme & $\begin{array}{l}\text { Yield } \\
\text { [t/ha] }\end{array}$ & $\begin{array}{l}\text { Above Ground } \\
\text { Dry Matter } \\
\text { [t/ha] }\end{array}$ & $\begin{array}{l}\text { Rooting } \\
\text { Depth } \\
\text { [cm] }\end{array}$ & $\begin{array}{l}\text { Stomatic } \\
\text { Water } \\
\text { Stress }\end{array}$ & $\begin{array}{l}\text { Turgescence } \\
\text { Water } \\
\text { Stress } \\
\end{array}$ & $\begin{array}{c}\text { Nitrogen } \\
\text { Stress } \\
(2)\end{array}$ \\
\hline obs. & observed $^{(1)}$ & 6.0 & 12.1 & 72.0 & - & - & - \\
\hline basic & basic parameterization & 0.96 & 2.28 & 14.8 & $\begin{array}{l}0.61 \\
0.38\end{array}$ & $\begin{array}{l}0.51 \\
0.37\end{array}$ & $\begin{array}{l}0.84 \\
0.72\end{array}$ \\
\hline (A) & $\begin{array}{c}\text { basic with } \\
\text { increased soil depth }\end{array}$ & 1.1 & 2.5 & 16.1 & $\begin{array}{l}0.62 \\
0.35\end{array}$ & $\begin{array}{l}0.52 \\
0.35\end{array}$ & $\begin{array}{l}0.85 \\
0.70\end{array}$ \\
\hline (B) & $\begin{array}{l}\text { (A) with } \\
\text { initialization }\end{array}$ & 1.1 & 2.5 & 16.1 & $\begin{array}{l}0.62 \\
0.35\end{array}$ & $\begin{array}{l}0.52 \\
0.35\end{array}$ & $\begin{array}{l}0.85 \\
0.71\end{array}$ \\
\hline (C) & $\begin{array}{l}\text { (B) with } \\
\text { artificial irrigation }\end{array}$ & 4.7 & 9.9 & 105.5 & $\begin{array}{l}0.93 \\
0.81\end{array}$ & $\begin{array}{l}0.75 \\
0.64\end{array}$ & $\begin{array}{l}0.90 \\
0.80\end{array}$ \\
\hline (D) & $\begin{array}{l}\text { (B) with } \\
\text { artificial fertilization }\end{array}$ & 1.1 & 2.6 & 16.1 & $\begin{array}{l}0.62 \\
0.35\end{array}$ & $\begin{array}{l}0.53 \\
0.35\end{array}$ & $\begin{array}{l}0.88 \\
0.73\end{array}$ \\
\hline (E) & $\begin{array}{l}\text { (B) with } \\
\text { artificial irrigation and artificial } \\
\text { fertilization }\end{array}$ & 5.3 & 11.3 & 105.5 & $\begin{array}{l}0.92 \\
0.81\end{array}$ & $\begin{array}{l}0.75 \\
0.64\end{array}$ & $\begin{array}{l}0.95 \\
0.87\end{array}$ \\
\hline (F) & $\begin{array}{c}\text { (B) with } \\
\text { optimized Q0 and } \\
\text { optimized ACLIM }\end{array}$ & 3.3 & 7.4 & 107.0 & $\begin{array}{l}0.91 \\
0.49\end{array}$ & $\begin{array}{l}0.83 \\
0.41\end{array}$ & $\begin{array}{l}0.93 \\
0.81\end{array}$ \\
\hline
\end{tabular}

curred, especially during the reproductive phase of the plant (Table 4, 'basic').

Studying the target variables, simulations would fail to run when exclusively yield-reducing parameter values (lower boundary condition) were considered for parameterization. Parameterizing exclusively yield-promoting values (upper boundary condition), on the other hand, resulted in maximum target values, although this was still clearly below the real yield measured in the field (Table $\mathbf{3}$ ).

\subsection{Model Behaviour}

Table 4 shows the effect of adjusting various model parameters on target variables and stress indices. Fig. (5 A-F) demonstrate the behavior of observed and modeled soil water content for each horizon (HR 1-4) after applying different types of parameterization schemes.

1. The soil condition was modified by increasing the soil depth; this was found to increase the yield somewhat, although the results are consistently below actual yield. A review of the stress indices shows that in year 2005 of the simulation, there was a sustained period of water stress which in turn entailed a period of nitrogen stress (see Table 4, run (A)). As can be seen in Fig. (5A), the first soil horizon reacts in a comprehensible manner to precipitation whereas the lower horizons appear not to be affected by this at all.

2. The consideration of state variables such as water and nitrogen at the beginning of the warm-up period is of secondary importance if initialization runs were made over the first three years and only the last year of the crop rotation was adopted in the analysis. The target variables from the basic parameterization could not be improved and again, spring barley suffers a remarkable water stress during its vegetative as well as its reproductive phase (see Table 4, run (B)). As before, modeled values for soil water content hardly correspond with the field data and the lower horizons seem not to be linked to the upper horizon (Fig. 5B). This can be traced back to the modeled poor rooting depth and as a result of this, there was no water removal from the lower horizons in the model.

3. Supplying artificial irrigation at a water stress index below 0.7 resulted in a significant improvement of the target variables. In contrast to the basic parameterization water stress is highly reduced, as shown in Table $\mathbf{4}$, run (C). The modeled soil water content shows a closer connection to the measured data: in the lower horizons a natural reaction to the supplemented water is noticeable whereas the upper horizon now shows less correlation to precipitation and measured values (Fig. (5C)).

4. Applying additional fertilizer did not result in any significant improvement of the target variables and stress indices, as can be concluded from Table 4, run (D). The shape of Fig. (5D) shows the same shortcomings as parameterization run $(\mathbf{A})$ and $(\mathbf{B})$.

5. The target variables increased further after combining artificial irrigation (water stress index 0.7 ) with artificial fertilization at medium nitrogen stress levels (stress index 0.7). The artificial supply of additional water as well as additional fertilizer causes the best matching results (Table 4, (E)). Comparable to the modeled soil water content of parameterization scheme $(\mathbf{C})$, the upper horizon demonstrates an unrealistic behavior, especially during the dry summer months (Fig, (5E)).

Overall, the parameterization schemes provided a closer approximation of the measured values; however, there is still 

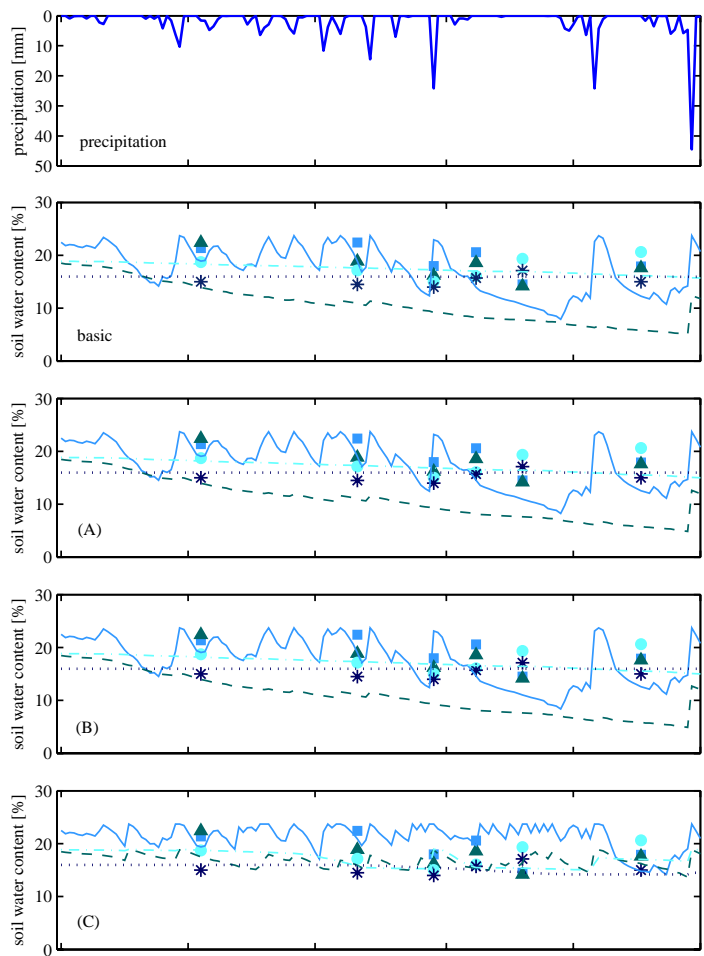
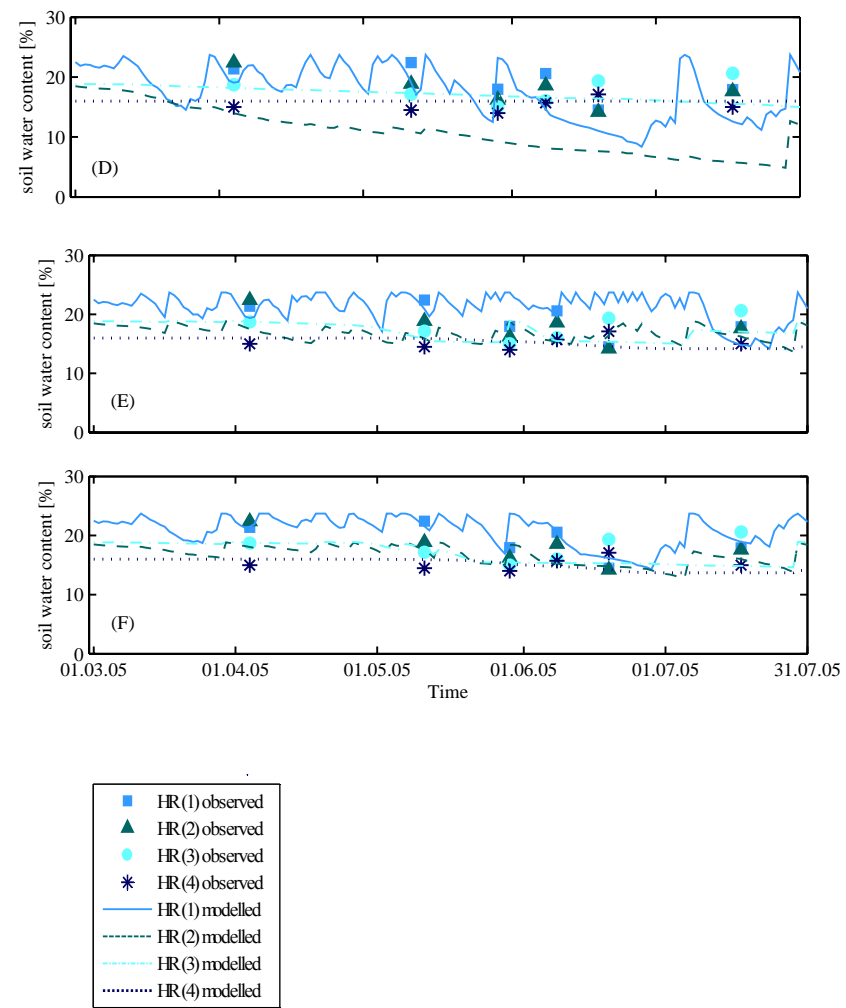

Figs. (5 A-F). Soil water content per horizon (HR) - observed versus modeled values.

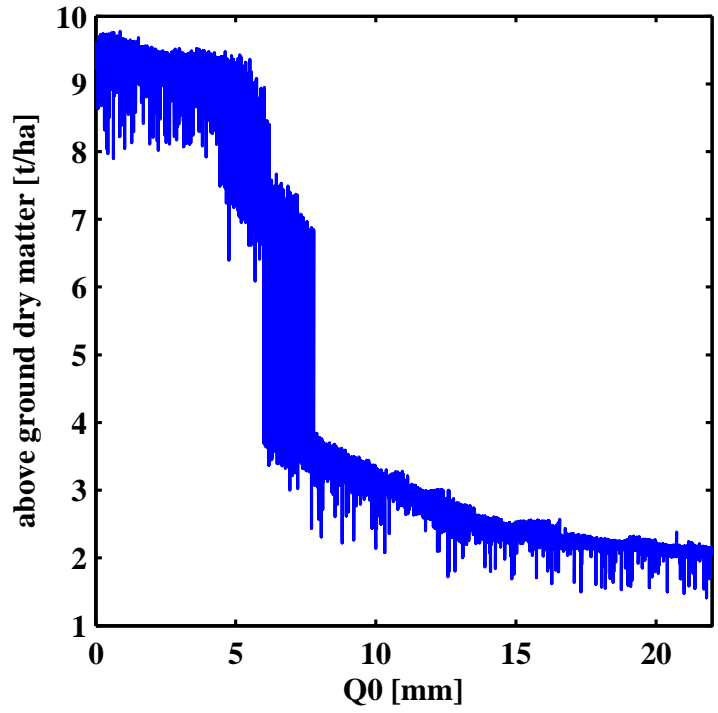

Fig. (6a). Comparing the distribution of above ground dry matter [t/ha] and Q0 [mm] using random variables for Q0 and ACLIM.

a gap between the model output and actual values obtained in the field, as shown in Table 4.

6. The Monte-Carlo simulations demonstrated that target variables (above ground dry matter and rooting depth) were found to be strikingly sensitive to the choice of Q0 and ACLIM. Figs. (6a) and (6b) show the effect of random combination of Q0 and ACLIM for above ground dry matter and rooting depth. Plotting the input variable Q0 and the target variables against each other a threshold level or switch is clearly visible, dividing the results into a lower section and a higher section. It can be concluded that values of $\mathrm{Q} 0<\sim 5$ lead to a stable and $\sim 5>$

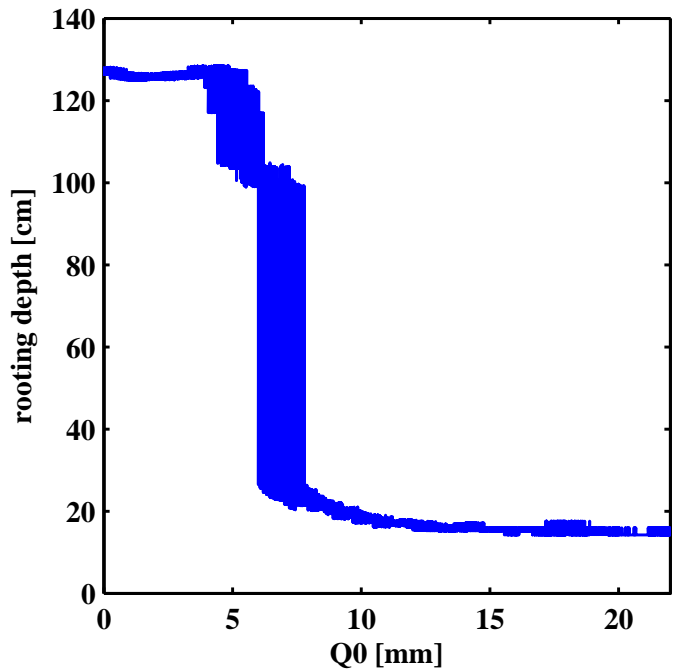

Fig. (6b). Comparing the distribution of rooting depth $[\mathrm{cm}]$ and $\mathrm{Q} 0$ $[\mathrm{mm}]$ using random variables for Q0 and ACLIM.

$\mathrm{Q} 0<\sim 8$ to an instable model behavior; values of $\mathrm{Q} 0>$ $\sim 8$ are not recommended as they cause extremely low above ground dry matter and very poor rooting depth (Figs. 6a and 6b). These threshold values demonstrate the highly non-linear behavior of the model.

Subsequently, the model was run with two contrasting values of Q0. It was found that high Q0 values (longer accumulation of daily potential evaporation after a rainfall event) lead to more frequent and more pronounced water stress during the vegetative stages of spring barley. This results in clearly visible delays in the spring barley's development (Figs. 7a and 7b). Moreover, a comparison of the phenological stages shows that an increase in Q0 causes delayed 
germination which in turn may adversely affect further stages of plant growth (the frequency and intensity of water stress increases as the summer approaches); in the present case, the emergence and early vegetative phases of growth were found to be severely impeded.

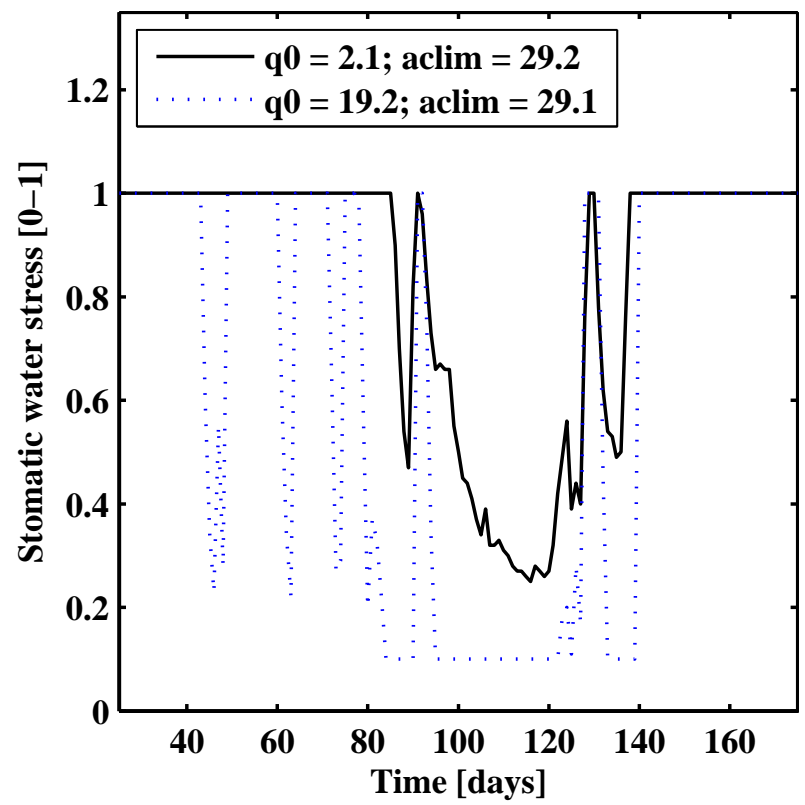

Fig. (7a). Intensity of stomatic water stress [0-1] using two contrasting pairs of variants for Q0 and ACLIM.

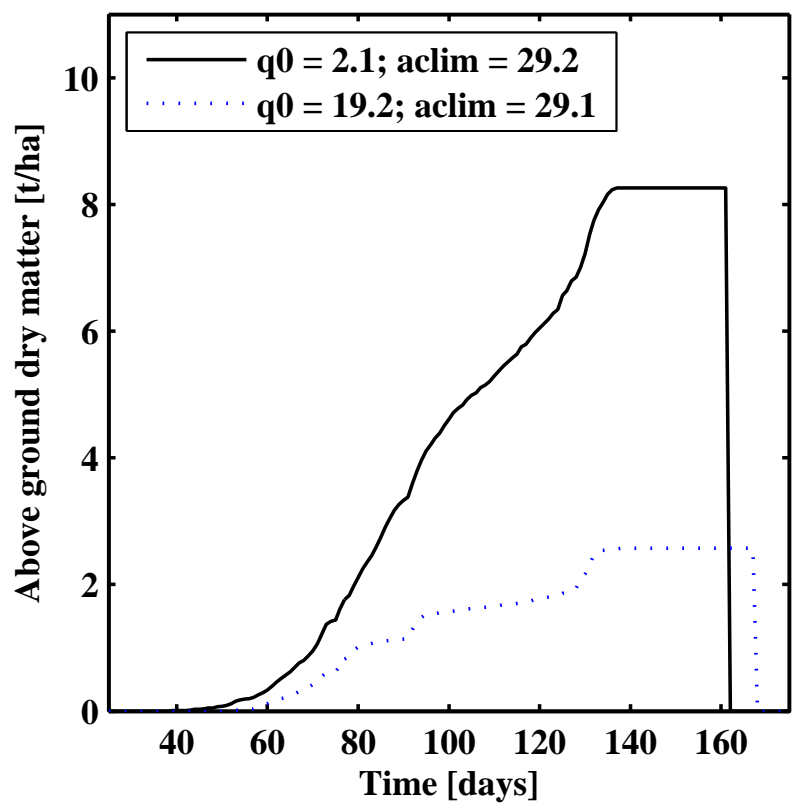

Fig. (7b). Development of above ground dry matter [t/ha] using two contrasting pairs of variants for Q0 and ACLIM.

Using a low Q0 value (brief accumulation of daily potential evaporation after a rainfall event) the simulated yield, above ground dry matter, and rooting depth are still somewhat lower than actual results but show a steady tendency towards the measured values (see Table $\mathbf{4}$, run $(\mathrm{F})$ ). Water stress during the vegetative phase of the plant is now hardly noticeable whereas water stress during the reproductive phase is still present albeit on a lower level compared to the basic parameterization. Thus, an advantageous calibration of Q0 can largely compensate artificial irrigation in the model. This is also confirmed in Fig. (5F): here, the upper soil horizon, HR (1), shows the same tendency as already known from the basic parameterization; dry periods however are still perceptible, in contrast to the results from artificial irrigation, see Fig. (5C). Again, the lower soil horizons show a comprehensible connection to the upper horizons (Fig. (5F)). To conclude it would seem that soil water content is now modeled close to reality.

\section{DISCUSSION}

Following a basic parameterization, the sensitivity of each soil module parameter was defined and upper boundaries of the target variables were determined. Subsequently, several attempts were made to optimize the target variables, including a Monte Carlo simulation for two parameters of high uncertainty.

Parameterizing the model based on the data collected in the field failed to provide realistic results. Beven [28] as well as Refsgaard et al. [29] named the problem of parameter uncertainty and correlated errors in the model predictions as well as the question of observation error in a modeling study. The present study attempted to address the problem of parameter errors by extending the basic parameterization scheme with simulation runs based on soil values which all minimize or maximize the target variables, respectively. However, even an idealized parameterization (upper boundary) taking into account the natural variance of the applied parameter values left a significant discrepancy between measured and modeled yield and above ground biomass. This mismatch mainly originates from heavy stomatic and turgescence water stress occurring in the simulation runs during the vegetative and primarily the reproductive phase of the plant.

Some of the approaches to model behavior resulted in at least partial improvements. Most effective in this respect was enabling artificial irrigation upon water stress. It is obvious though that the soil water balance has a decisive role in the model structure. The results of the preliminary sensitivity study emphasize this aspect. On closer examination of the most sensitive parameters in the soil module, it becomes evident that these model parameters - water content at field capacity and at wilting point, real evaporation from soil and soil depth - are mainly responsible for the soil water balance in the natural system. The strong impact of these parameters in the model structure is therefore not surprising, but great care must be taken when attempting to parameterize the soil module, which should be classified as highly sensitive. On the other hand the soil module also seems to be sensitive to climatic conditions. This signalizes the fact that parameter Q0 causes a highly non-linear behavior of the plant growth model, as inferred from the Monte Carlo analysis, because it has a remarkable influence on the actual evaporation of the soil. Artificial irrigation may serve to compensate for the effects of an overestimated Q0, but it is an artificial intervention in model parameterization, which does not correspond to real conditions and is therefore not desirable. The optimized value of $\mathrm{Q} 0$, that is $\mathrm{Q} 0=<5$, is not consistent with the in- 
formation from literature but neighbors the recommended range of Q0.

Summarizing the approaches to model behavior it has to be concluded that only by a strong reduction of simulated water stress realistic results could be achieved. So the water balance has a key position in the STICS model; other parameters are of secondary importance.

\section{CONCLUSION}

The water balance and the soil water balance in particular, turned out to be the central and decisive factors. The close link between water balance and crop growth thoroughly corresponds to the real system. The inner structure of the soil module, on the other hand, turned out to be problematic. At any rate, the complex structure of the model requires careful and intense examination of the model parameters.

In light of the model's sensitivity to climatic conditions it is strongly recommended to validate and, if needed, to calibrate the Q0 parameter, as it turned out to be an effective parameter. This concerns in particular dry summer months with low precipitation and high temperatures, where even average values for Q0 cause a relatively substantial evaporation from soil. According to the model, the remaining water infiltrating the soil is insufficient to the plant which suffers water stress and becomes stunted. This does not agree with field observations.

It was shown that parameterizing a model based on field data and information available in the literature may be enough to run a model, however broad knowledge of the real system as well as the model structure is of crucial importance in order to reliably validate the model results. An intensive analysis of the model's sensitivity and its specific inner structure is therefore strongly recommended. This corresponds with the approach of behavioral modelling as recently introduced by [30]. The various approaches to parameterize the soil module proved helpful to familiarize with the module and to detect sensitive parts of the model. In the case of the crop model STICS, the different stress indices turned out to be useful indicators to make statements about the model's closeness to the natural system.

\section{ACKNOWLEDGMENT}

The authors would like to thank the INRA for providing STICS and giving very friendly and helpful support throughout the time of working with the model.

\section{REFERENCES}

[1] Franko U, Oelschlägel B, Schenk S. Simulation of temperature-, water- and nitrogen dynamics using the model CANDY. Ecol Model 1995; 81: 213-22.

[2] Christiansen JS, Thorsen M, Clausen T, Hansen S, Refsgaard JC. Modelling of macropore flow and transport processes at catchment scale. J Hydrol 2004; 299 (1): 136-58.

[3] Schnebelen N, Nicoullaud B, Bourennane $\mathrm{H}$, et al. The STICS model to predict nitrate leaching following agricultural practices. Agron Sustain Dev 2004; 24: 423-35.

[4] Diekkrüger B, Söndgerath D, Kersebaum KC, McVoy CW. Validity of agroecosystem models. A comparison of results of different models applied to the same data set. Ecol Model 1995; 81: 3-29.

[5] Smith P, Smith JU, Powlson DS, et al. A comparison of the performance of nine soil organic matter models using datasets from seven long-term experiments. Geoderma 1997; 81: 153-225.
[6] Kersebaum KC, Hecker JM, Mirschel W, Wegehenkel M, Eds. Modelling water and nutrient dynamics in soil-crop systems: Applications of different models to common data sets. Springer: Dordrecht: The Netherlands 2007.

[7] Kersebaum KC, Wenkel KO. Modelling water and nitrogen dynamics at three different spatial scales - influence of different data aggregation levels on simulation results. Nutr Cycl Agroecosys 1998; 50: 313-9.

[8] Kersebaum KC, Lorenz K, Reuter HI, Schwarz J, Wegehenkel M, Wendroth O. Operational use of agro-meteorological data and GIS to derive site specific nitrogen fertilizer recommendations based on the simulation of soil and crop growth processes. Phys Chem Earth 2005; 30 (1-3): 59-67.

[9] Franko U, Kuka K, Romanenko IA, Romanenkov VA. Validation of the CANDY model with Russian long-term experiments. Reg Environ Change 2007; 7: 79-91.

[10] Ledoux E, Gomez E, Monget JM, et al.. Agriculture and groundwater nitrate contamination in the Seine basin. The STICSMODCOU modelling chain. Sci Total Environ 2007; 375 (1-3): 3346.

[11] Brisson N, Mary B, Ripoche D, et al.. STICS: a generic model for the simulation of crops and their water and nitrogen balance. I. Theory and parameterization applied to wheat and corn. Agronomie 1998; 18: 311-46.

[12] Brisson N, Ruget F, Gate P, et al. STICS: a generic model for the simulation of crops and their water and nitrogen balance. II. Model validation for wheat and maize. Agronomie 2002; 22: 69-92.

[13] Brisson N, Gary C, Justes E, et al. An overview of the crop model STICS. Eur J Agron 2003; 18: 309-32.

[14] Brisson N, Dorel M, Ozier-Lafontaine H. Effects of soil management and water regime on the banana growth between planting and flowering. Simulation using the STICS model. Acta Hortic 1997; 490: 229-38.

[15] Affholder F, Scopel E, Neto JM, Capillon A. Diagnosis of the productivity gap using a crop model. Methodology and case study of small-scale maize production in central Brazil. Agronomie 2003; 23 (4): 305-25.

[16] Hadria R, Khabba S, Lahrouni A, et al. Calibration and validation of the STICS crop model for managing wheat irrigation in the semi-arid Marrakech / Al Haouz Plain. Arab J Sci Eng 2007; 32 (1C): 87-101.

[17] Godard C, Roger-Estrade J, Jayet PA, Brisson N, Le Bas C. Use of available information at a European level to construct crop nitrogen response curves for the regions of the EU. Agric Syst 2008; 97 (12): $68-82$.

[18] Meyen E. Bitburger Gutland. In: Meyen E, Schmithüsen J, Eds. Handbuch der Naturräumlichen Gliederung Deutschlands. Bundesanstalt für Landeskunde und Raumforschung: Bad Godesberg 1962.

[19] Richter G. Der Landschaftsraum Tier. In: Jätzold R, Ed. Der Trierer Raum und seine Nachbargebiete. Trierer Geogr. Studien 1984; vol. 6: pp. 89-94.

[20] DWD / Deutscher Wetterdienst, Ed. Mittelwerte der Station TrierPetrisberg für die Periode 1961 bis 1991. @ Deutscher Wetterdienst: Offenbach am Main 2008.

[21] Ritchie JT. Model for predicting evaporation from a row crop with incomplete cover. Water Resour Res 1972; 8: 1204-13.

[22] Brisson N, Perrier A. A semiempirical model of bare soil evaporation for crop simulation models. Water Res 1991; 27: 719-27.

[23] Brisson N, Launay M, Mary B, Beaudoin N, Eds. Conceptual basis, formalisations and parameterization of the STICS crop model. Éditions Quae: Versailles 2009.

[24] Oke TR. Boundary Layer Climates. $2^{\text {nd }}$ ed., Routledge: London 1996.

[25] Ad-Hoc AG Boden / Bundesanstalt für Geowissenschaften und Rohstoffe und Geologische Landesämter, Bodenkundliche Kartieranleitung. $5^{\text {th }}$ ed. Schweitzerbart: Stuttgart 2005.

[26] Scheffer F, Schachtschabel P. Lehrbuch der Bodenkunde. $14^{\text {th }}$ ed., Enke: Stuttgart 1998.

[27] Saltelli A, Chan K, Scott EM. Sensitivity analysis. John Wiley \& Sons: Chichester, England 2000.

[28] Beven KJ. Working towards integrated environmental models of everywhere: uncertainty, data and modelling as a learning process. Hydrol Earth Syst Sci 2007; 11 (1): 460-7. 
[29] Refsgaard JC, van der Sluijs JP, Brown J, van der Keur P. A framework for dealing with uncertainty due to model structural error. Adv Water Resour 2006; 29: 1586-97.
[30] Schaefli B, Harman CJ, Sivapalan M, Schymanski SJ. Hydrologic predictions in a changing environment: behavioural modeling. Hydrol Earth Syst Sci 2011; 15: 635-46.

(C) Heuer and Casper; Licensee Bentham Open.

This is an open access article licensed under the terms of the Creative Commons Attribution Non-Commercial License (http://creativecommons.org/licenses/by-nc/3.0/) which permits unrestricted, non-commercial use, distribution and reproduction in any medium, provided the work is properly cited. 